\title{
The Status of Laser Diagnostics Supporting Ion Thruster Development at NASA GRC
}

\author{
George J. Williams, Jr. ${ }^{*}$ \\ OAI / NASA Glenn Research Center \\ 21000 Brookpark Rd. \\ Cleveland, $\mathrm{OH} 44135$
}

\author{
Sarah N. Ray \\ Dept. of Aerospace Eng. \\ Univ. of Michigan \\ Ann Arbor, MI 48109
}

\author{
Matthew T. Domonkos \\ NASA Glenn Research Center \\ 21000 Brookpark Rd. \\ Cleveland, OH 44135
}

\begin{abstract}
In order to measure sputtered atoms and plasma properties which lead to erosion in ion thrusters, laser diagnostics are being incorporated in the NASA Glenn Research Center's ion propulsion development program. Laser diagnostic capabilities include UV and IR laser-induced fluorescence and laser interferometry. Objectives of the diagnostics, issues associated with their implementation, and paths to reach the objectives are presented.
\end{abstract}

\section{Introduction}

Ion thrusters are being scaled to different powers and operating conditions for a variety of space flight applications. Several wear-tests have been conducted to demonstrate long duration operation and determine life-limiting phenomena. ${ }^{1,2,3,4}$ Some of the potential failure mechanisms identified during these tests resulted from erosion of thruster components due to ion impact. The scaling of ion thrusters to higher powers may result in erosion sufficient to preclude certain mission applications. In addition, engine throttling for solar electric propulsion (SEP) missions complicates lifetime predictions from wear tests as the erosion is compounded from one operating condition to another. The time and cost required to validate thruster life at each throttle condition are prohibitive. ${ }^{5}$ In situ, realtime erosion-rate and plasma diagnostics appear to have the potential of enabling lifetime evaluation at different throttling conditions with minimal time and cost.

Several probe measurements are consistently made in the mid to far field plume during ion thruster wear tests and performance evaluation tests. Data provided by these measurements are used in first order numerical models to predict the erosion. However, until a substantial database of predicted versus observed erosion has been established to validate the numerical models, long-duration life tests will be required to minimize operational risk.

Limited internal Langmuir probe and laser-induced fluorescence (LIF) data have been collected using modified ion thrusters and ion thruster components. ${ }^{6,7}$ While valuable as indicators of mechanisms leading to thruster erosion, the actual erosion of high-fidelity hardware is not determinable from these measurements. Table 1 lists sites of erosion and related plasma parameters. State of the art (SOA) diagnostic capabilities for these and issues associated with direct measurement of them via laser diagnostics are also given. Note that the primary limitations are restricted optical access and laser beam diameter.

Because laser diagnostics have the potential of reducing development time and costs and of providing fundamental insights, the ion propulsion group at the NASA Glenn Research Center (GRC) has established a two prong laser diagnostic development program. One is concerned primarily with the direct measurement of eroded atoms and the other with plasma property measurement. In addition, universities are being funded by GRC to pursue subscale tests and high-speed internal probe measurements. Extensive numerical modeling of the erosion processes and plasma

\footnotetext{
Member, AIAA

$\dagger$ Senior Member, AIAA
}

This material is declared a work of the U.S. government and is not subject to copyright protection in the United States. 
properties are also being developed (with and without GRC support) and evaluated.

This paper reviews the laser diagnostic program in the ion group at GRC. Specifically, the programs objectives are reviewed and issues with the realization of these objectives are discussed. After reviewing the ion team's laser diagnostic capabilities, two targets of investigation are discussed in detail: grid erosion and discharge cathode assembly erosion. It is hoped that this review will indicate avenues of laser diagnostic research of particular interest to ion thruster lifetime evaluation.

\section{Laser Diagnostic Capabilities}

In the last two years, a laser diagnostic capability has been developed in the ion group at GRC. The capability has been divided into two principal thrusts: the direct, calibrated measurement of eroded atoms and the characterization of the plasma near regions of erosion. Both of these are intended to provide a realtime, non-intrusive lifetime assessment of ion thrusters. In addition, both labs may provide insight into fundamental physics associated with ion thruster operation. The two thrusts are supported by two new laboratories at GRC which leverage the expertise of personnel at the lab.

\section{High-Power Laser Diagnostics Laboratory}

The High-Power Laser Diagnostics Laboratory is primarily dedicated to the direct measurement of eroded species such as Mo and Ti. The lab incorporates an Nd:YAG pumped dye laser which is doubled into the UV. ${ }^{5}$ UV pulse energies have been demonstrated up to $1.5 \mathrm{~mJ} /$ pulse or approximately $150 \mathrm{~kW}$ operation. The laser system has demonstrated a UV tuning range of approximately $\pm 10 \mathrm{~nm}$ with less than a fifty percent loss in power.

Figure 1 provides a schematic of the pulsed laser system. Note that fiber optics are used to transmit the beam from the lab to the test facility. Fluorescence in the test chamber will be collected with a gated intensified CCD (ICCD) camera. The collection optics form a collimating telescope inside the chamber. A final focusing lens located outside of the chamber sends the light through a $0.5 \mathrm{~m}$ monocromator and into the ICCD. Both the laser delivery optics and the collection optics are fixed prior to facility pump down.

The $345.6 \mathrm{~nm}-550 \mathrm{~nm}$ Mo ground state transition has been demonstrated as a potential erosion diagnostic using phase-locked LIF in table top experiments at GRC. However, three factors have precluded in situ measurements to date. These include the lack of post- evacuation laser alignment verification mechanism, poor delivery of laser power to the facility, and relatively poor beam quality which yields a relatively large spot size $(0.25 \mathrm{~cm}$ diameter spot $)$ at the point of interrogation.

Each of these factors is currently being addressed. Alignment is being facilitated by a crosshair mounted on a probe positioning system. The doubling efficiency of the beta barium borate (BBO) crystal may be significantly improved via the incorporation of a specially designed alignment apparatus. Direct beam delivery should improve both delivered power and beam quality. The impact and limitations of these approaches are discussed below.

\section{Laser-based Plasma Diagnostics Laboratory}

The Laser-based Plasma Diagnostics Laboratory is primarily concerned with non-intrusive plasma characterization. Techniques for measuring species velocities and relative densities are being incorporated or developed. This lab is centered around a 0.5 Watt tunable diode laser. The laser has a center wavelength of $840 \mathrm{~nm}$, has a coarse tuning range of $+5 \mathrm{~nm}$ and -15 $\mathrm{nm}$ and has recently been upgraded to a $30 \mathrm{Gz}$ modehop-free fine tuning capability. In addition, the lab incorporates low power $(20 \mathrm{~mW}) \mathrm{HeNe}$ lasers for nonresonant interferometric measurements.

\section{Laser-Induced Fluorescence}

In principal, the diode laser will be capable of interrogating many species of interest via LIF. Table 2 lists different species and the associated transitions for plasma interrogation and an excited Mo state which might also be useful. To date, bench top Xe II LIF and Xe I bench top opto-galvanic spectroscopy (OGS) have been demonstrated. Recall that OGS consis ts of measuring the change across a leg of voltage divider consisting of a hollow cathode lamp with the species of interest and a high power resister. As the laser is tuned through an electronic transition in the constituent gas, the resistance of the lamp will decrease.

Figure 2 provides a schematic of the diode laser, LIF beam preparation, beam delivery and signal collection. The layout is similar to that used previously with a cw ring dye laser to characterize ion thruster plasmas. ${ }^{6}$ The laser is sampled twice to measure instantaneous power and wavelength and then split into two beams. Each of the split beams is chopped at different frequencies to permit phase-locked detection of the induced fluorescence and then coupled into optical fibers. The two fibers are run to the vacuum facility where the laser beams are focused at an interrogation point allowing simultaneous measurement of two velocity components. One of these beams is sampled 
and sent through an opto-galvanic lamp which has the target species. The induced fluorescence in the optogalvanic cell and in the vacuum chamber are collected on photo-multiplier tubes (PMTs) mounted to small monochromators. The induced fluorescence is resolved from the background natural fluorescence via lock-in amplifiers.

A data acquisition and analysis system is being developed to control experiments for plasma characterization via a main computer interface. This system will provide a graphic display of separate functions of intensity versus the Laser Induced Fluorescence (LIF) signal, ion velocity and energy. A voltage generator with $.0001 \mathrm{~V}$ increment capabilities is used to fine-tune the diode laser. Programs were written to scan the voltage source over a specified window, plot several channels against the wavelength of the laser, take multiple scans and average them, and write the raw data to a spreadsheet file. An icon-based coding software was implemented to accomplish this. The system will improve the efficiency of the LIF experiments, as it will facilitate data analysis and enable sensitive, repeatable measurements. The voltage generator provides a slow scan allowing the lock-in amplifiers to filter noise.

\section{Laser Interferometry}

In addition to LIF, interferometric techniques are being explored to more accurately measure the electron number densities and the densities of species in the plasma. In particular the technique of laser deflection interferometry (LDI) has been developed by Kovaleski and Willimas. 8 This technique overcomes limitations in minimum number density present in classic laser interferometry and laser deflection techniques by using the inherent sensitivity of the interferometer to measure the deflection of the laser through the plasma. Figure 3 shows a schematic of a Mach-Zehnder interferometer set up for cathode plume measurements. Figure 4 shows the effect of a small deflection of one of the beams on the spacing of the Fizeau fringes of the interferrogram. The change in fringe spacing is proportional to the gradient in the electron number density (non-resonant laser wavelength): ${ }^{8}$

$$
\int_{\text {path }} \frac{\mathrm{dn}_{\mathrm{e}}}{\mathrm{dz}} \mathrm{ds}=\frac{4 \mathrm{n}_{\mathrm{c}} \lambda}{\Delta \mathrm{X}_{\mathrm{u}}}\left(\frac{\Delta \mathrm{x}}{\mathrm{x}}\right)=\mathrm{dn}_{\mathrm{e}} \mathrm{s}
$$

where $n_{e}$ is the electron number density, $z$ is the longitudinal direction, $x$ is the fringe spacing, $X_{U}$ is the fringe spacing at the point of interrogation, $\mathrm{n}_{C}$ is the cutoff number density, and $\lambda$ is the laser wavelength.
Ultimate resolution of this technique is determined by the resolving power of the recording device for a given laser wavelength. However, the resolution can be enhanced by amplifying the deflection introduced by the plasma. For instance, multiple reflections off of a defraction grating can increase the sensitivity by several orders of magnitude which may make it a practical diagnostic technique for ion thruster plasma densities on the order of $10^{11}$ to $10^{14} \mathrm{~cm}^{-3}$.

\section{Grid Erosion}

The mechanisms leading to ion impingement on the screen grid and the accelerator grid are significantly different and, therefore, present different challenges for real time erosion measurements. The mechanisms themselves, however, are relatively well understood.

\section{Erosion Mechanisms}

\section{Screen Grid}

The screen grid is eroded by two mechanisms. One is the impingement of ions which are accelerated through the edges of a detached sheath which focuses ions through the two-grid assembly. Both singly and doubly charge ions contribute to this erosion which results in a chamfer on the upstream edge of the screen grid apertures. ${ }^{3}$ The second mechanism is the impingement of ions falling through the sheath covering the remainder of the upstream surface of the electrode. Since the fall from the discharge plasma potential to the screen grid is on the order of the sputtering threshold, it is believed that most of this erosion is caused by doubly charged ions. For most near term applications with state of the art configurations, the erosion of the screen grid is not mission limiting. ${ }^{3}$ However, for very long duration missions or under different operating conditions, such as higher discharge voltages ${ }^{9}$ or different electrode biases, ${ }^{1}$ the erosion could be significant.

Because of the difficulty in observing the screen grid during operation, erosion predictions are typically based on performance parameters such as discharge voltage and screen grid current and on downstream Faraday and ExB probe measurements. Optical emission spectroscopy has been used to predict the erosion rates, ${ }^{10}$ but that method is limited by assumptions regarding (or the need for measurements of) plasma parameters such as ambient density, thermodynamic state, and electron temperature. It is also complicated by the fact that the accel grid is typically of the same material and its larger erosion rates might mask the screen erosion. Thin film badges require tests of relatively long duration (tens of hours) and, like long wear tests, prohibit the distinction 
between normal wear rates at particular operating conditions and wear rates during transients or abnormal operating conditions. ${ }^{11}$

\section{Accelerator Grid}

Accelerator grid erosion has been identified as a primary path to engine failure. ${ }^{12}$ Charge exchange ions impact both the downstream surface and the aperture walls of the grid. The downstream impingement results in the well documented ${ }^{13}$ and heavily modeled ${ }^{14,15}$ pit and groove erosion pattern. The pits are not considered life threatening, but the grooves may lead to structural failure of the grids and/or a permanent short between the electrodes. Both are caused by singly charged, charge exchange ions impacting the surface at nearly normal incidence at energies roughly equal to the magnitude of the accelerator grid voltage $(\sim 200 \mathrm{~V})$ Figure 5 shows photographs of the accelerator grid illustrating the erosion. Aperture diameter enlargement may also lead to engine failure when the apertures become so large that the negative voltage applied to the accelerator gird is no longer sufficient to prevent electron backstreaming. Recent modeling of charge exchange ion production and ray tracing from creation to impact ${ }^{16}$ indicates that aperture enlargement results from the impact of charge exchange ions created throughout the screen to accelerator gap. Some of the ions have energies on the order of the beam voltage and strike at a variety of angles.

While the downstream surface of the accelerator grid is readily accessible, the erosion rates are so slow that aperture imaging and profilometry still require hundreds of hours of operation to resolve changes. As with the screen grid, lifetime predictions and modeling are typically based on plume measurements of the beam profile and the doubly to singly charge ion fractions. LIF has been demonstrated as a real-time accel grid erosion diagnostic technique, ${ }^{5,11}$ but it has yet to be implemented as a supplement to wear testing.

\section{Laser diagnostics}

Real-time measurements of the density of eroded species and of the density and velocity of different plasma species (e.g. Xe I, Xe II, and Xe III) would enable detailed evaluation of the erosion rates and their dependence on thruster operating condition. Areas of primary interest for laser interrogation are along the upstream surface of the screen grid, along the aperture walls of the accel grid and along the groove regions of the accel grid. The resolution should be sufficient to resolve localized erosion to the point that the variation in erosion across the radius of the grids can be determined and sufficient to resolve where the erosion is taking place. This applies to sputtered materials and to plasma properties. Locations of particular interest are the screen grid surface, accelerator aperture walls, and the grooves on the downstream surface of the accelerator grid. As indicated above, the global goal has been divided into direct eroded species measurement and plasma characterization.

Ground state Mo LIF is being pursued with the pulsed dye laser. Interrogation of the groove region is perhaps the most straight-forward. Laser spot sizes consistent with the required resolution have been demonstrated upstream of the fiber optics. Eventually, limitations in both interrogation and collection spatial resolutions may be mitigated via planar LIF (PLIF) in which a region of fluorescence will be imaged on the ICCD camera. $^{5}$ This would remove many of the potential costs and delays associated with single point interrogation. LIF data with spatial resolutions of a few apertures will be achieved. This measurement would provide a significant increase in the real time evaluation of accel grid erosion. Concurrent with this would be the development of a calibration capability such as the one currently being pursued at GRC. ${ }^{17}$ Failure to calibrate the LIF signal would not preclude its usefulness as a relative diagnostic but would introduce significant uncertainties when comparing data taken using different hardware and when predicting the absolute life of a grid under particular operating conditions. It would, for instance, remain a valuable tool for evaluating the effect of back-sputtered deposition on the erosion of a set of grids.

Relatively large aperture optics (such as those used for very high powers and Isp (> $10000 \mathrm{~s})^{18}$ will facilitate the development of the grid erosion diagnostic. While clearly making it easier to achieve an interrogation cross section small enough to differentiate between pit and groove and aperture wall erosion, the larger grids, which will have larger grid to grid gaps, may also provide a path to measure the screen grid erosion. This path might be either through the side of the ground screen or via an extreme angle through the accel grid.

The dye laser can interrogate Xe III using the $336 \mathrm{~nm}$ 490nm transition without a dye change. While the halfwidth of the UV laser is orders of magnitude greater than that of the diode laser, benchtop measurements indicate that the dye laser can resolve significant velocities as well as relative densities of the Xe III. As discussed below, Xe III is believed to be the leading cause of internal erosion and the ability to resolve the radial distribution of relative Xe III to Xe II fractions would significantly improve the predictive capabilities of screen grid life. Very near-field measurements of $\mathrm{n}^{++} / \mathrm{n}^{+}$would be more useful and significantly less intrusive than a relatively near-field ExB probe with a quick scanning capability. 
Ion velocity measurements near the grids suffer from the same resolution issues as the erosion products measurements. In addition, velocity and density measurements with poor spatial resolution will add very little to the understanding of the erosion process. PLIF is not as straight forward a solution for velocity measurements as it is for density measurements. A series of still shots collected from the side of the thruster at different laser wavelengths may yield a twodimensional velocity map of the ions. Very tight control of the alignment would require mounting the thruster on an $\mathrm{x}-\mathrm{y}$ positioning table.

Singly charged xenon ion velocity measurements have been demonstrated across the accel apertures at the University of Michigan using a chopped cw dye laser and the $605 \mathrm{~nm}-540 \mathrm{~nm}$ transition. Both side-on multiplex ${ }^{6}$ and end-on single beam $^{19}$ delivery techniques have been used. Both methods may be employed at GRC as well.

Since the diode laser system in the laser diagnostics lab has never been used for low-density plasma velocimetry, this capability is being demonstrated in the downstream plume of a HCA in a relatively small vacuum facility. The small facility affords hands on access to all optics during testing. The same laser beam conditioning and fiber delivery scheme illustrated in Fig. 2 is used. Although laser power delivered to the chamber is believed to be sufficient for LIF, poor control of the laser wavelength prior to the tuning upgrade and lack of a data acquisition system coupled to the laser tuning (recently remedied) have precluded LIF demonstration.

Once the LIF velocimetry diagnostic tool has been demonstrated, it will be implemented in a series of steps for near-grid plasma characterization. For interrogation cross-sections on the order of accel grid apertures, Xe II LIF will provide the best measure of beam flatness (i.e. the variation in beamlet current density across the diameter of the thruster). Multiplex velocimetry with this resolution might also provide a velocity spectrum tied to beam divergence.

Smaller LIF interrogation cross-sections will be required to validate numerical models of the accelerator erosion. Deconvolution and filtering of the fluorescence spectrum might resolve charge-exchange ions impacting the surface of the grids. ${ }^{20}$ Deconvolution, illustrated in Fig. 6, requires knowledge of the fine structure constants of the transition. An effort is underway at the University of Michigan to experimentally determine these for the $834.7 \mathrm{~nm}$ transition given in Table $2 .^{21}$
While the measurement of relative densities of excited states for a given test is straightforward, the conversion of this data to even relative densities of the particular species (e.g. Xe I or Xe II) for different tests is not. Since the IR states are far removed from the ground state, the approximation of partial thermodynamic equilibrium may be valid. ${ }^{22}$ The relative intensities from one test to the next must be calibrated to a constant (if unknown) number density. A small reference cell with a glow discharge placed in the vacuum chamber near the thruster will be used.

To an even greater ext ent than with the sputtered atom interrogation, large aperture optics may provide the best path to collect experimental Xe I, Xe II and Xe III data to validate and support the development of numerical codes predicting grid erosion rates. Intra-aperture resolution should be possible as well as access to the discharge plasma upstream of the sheath formed across the screen grid aperture (to potentially measure Xe I, $\mathrm{Xe}$ II and $\mathrm{Xe}$ III relative densities in the discharge plasma). However, it is not clear how velocities of ions impinging on the screen grid can be measured.

Single-point, intra-aperture resolution on grids with NSTAR-like aperture geometries will require a very small beam waist which has yet to be demonstrated with this laser. As with the UV interrogation, PLIF may provide a solution via the tune and shoot method mentioned above.

To the extent possible, the plasma diagnostics will be demonstrated using thruster sub-assemblies in small vacuum chambers. Opportunities will be taken to couple the LIF measurements to other investigations in these smaller facilities as time permits.

\section{Discharge Cathode Assembly Erosion}

The discharge cathode assembly (DCA) including the cathode orifice plate and the cathode keeper has exhibited different degrees of erosion in different wear tests. $1,2,3,4$ The differences highlight the need for a real-time diagnostic to relate the erosion to the immediate operating condition.

Figure 8 shows the erosion of the unkeepered DCA following a segment of the 2000 wear test. ${ }^{1}$ LIF investigations at the University of Michigan identified low-energy back flowing ions and higher energy radially flowing ions which suggest the observed erosion resulted from a combination primarily doubly charge ions following these same fluxes. ${ }^{6}$ The 
correlation between the observed erosion and the measured ion velocities is also given in Fig. 8. Retraction of the heater behind the plane of the cathode orifice plate and especially the introduction of a keeper electrode to shield the orifice plate were believed to have provided an engineering solution. 2,3

The keeper electrode did exhibit erosion during the $8200 \mathrm{hr}$ wear test suggesting that as ion thrusters are scaled to higher powers and designed for longer operation lifetimes, the DCA erosion may still be of concern. ${ }^{3}$ In addition, significant erosion of the discharge keeper occurred during the NSTAR Extended Life Test (ELT). ${ }^{4}$ The erosion is summarized in Figure 9.

There are two principal theories regarding the cause of the erosion during the ELT. One suggests that the erosion was radically different from that previously observed, was initiated from increased $\mathrm{Xe}$ III production near the cathode during a throttled operating condition, and continued at an increased rate due to continued high Xe III production. ${ }^{4}$ The onset of the erosion was potentially augmented by a short of the keeper to cathode potential for a segment of the throttled operating condition. However, the $\mathrm{j}^{++} / \mathrm{j}^{+}$ fractions measured in the plume were substantially smaller for throttled operation. ${ }^{4}$ LIF $^{6}$ and $\mathrm{OES}^{23}$ indicate that the erosion rates are smaller for throttled operation as well. An alternative theory suggests that the short resulted in moderately accelerated erosion as a larger fraction of the Xe III flux then impacted above the sputtering threshold significantly increasing the keeper orifice diameter. The region near the cathode orifice transitioned from parameters of keepered towards unkeepered operation. It is suggested that ions within the keeper orifice begin to exhibit large radial velocities observed experimentally ${ }^{6}$ and further increased the erosion. Regardless, prediction and measurement of keeper/cathode erosion has become as important as accelerator grid erosion for higher-power, longer life thruster development.

\section{Laser diagnostics}

The objectives of real-time measurements of eroded species and plasma parameters near the DCA are similar to those for grid erosion-rate measurements. Sputtered atom densities across the radius of the keeper and within the keeper orifice have less restrictive spatial resolution requirements than grid erosion measurements. Also, plasma densities are much higher than near the grids facilitating LIF signal strength. However, the velocity measurements will require significantly higher velocity resolution since the energies of the ions will be on the order of a few to several eV. ${ }^{6}$ Since subtle changes in the construction, magnetic circuit, and operating conditions of the discharge chamber may impact the DCA erosion rates, the ultimate goal of GRC's diagnostic effort is to develop a technique that can be applied through the grids of the thruster thereby requiring no physical modification of the thruster.

Because of the complications introduced by attempting laser diagnostics through the grids, the initial evaluation of DCA erosion will be conducted on engineering model thrusters modified for optical access through the walls of the discharge chamber. This follows a similar path as the pre-engineering, functional model thruster (FMT) used in previous DCA erosion investigations. ${ }^{6}$ Direct optical access is preferred to fiber optics because it provides a large collection solid angle to detect the weak induced fluorescence and because it facilitates fine spatial translation of the point of interrogation.

The application and calibration of the lasers for LIF measurements will be similar to that described above for grid region measurements. Determination of the distribution of erosion across the face of the DCA is complicated by he diffuse and lobed nature of the sputtered efflux. ${ }^{24}$ Thus, unless the eroded species is measured immediately at the surface, there may be a significant uncertainty in the correlation of measured atom density and the location of the erosion. However, as noted above, spatial resolution less than the keeper orifice diameter will not be required to determine if the DCA is eroding at a less or greater rate.

Identification of separate populations of ions moving towards and away form the DCA surface is complicated by optical access even with windows on the discharge chamber. Previous multiplex velocimetry was unable to detect different populations and was subject to large axial velocity uncertainties because of the small angle required to pass two beams through a single lens to insure interrogation at the same location. ${ }^{6}$ A different optical delivery scheme will be incorporated in future measurements. Demonstration of the ability to perform velocimetry near the DCA by passing a beam through the grids may be forthcoming from the University of Michigan. 19

Characterization of the plasma in the discharge chamber and the plasma associated with other EP devices will follow either as part or in preparation for the above measurements. The principal benefit of this will be data to support the development of numerical models. However, the characterizations will also provide a means of validating the laser techniques as 
many of the plasmas will be amenable to alternative diagnostics.

\section{Summary}

Efforts are underway at GRC to develop and implement laser diagnostic techniques capable of providing realtime assessment of ion thruster wear mechanisms. Emphasis is being placed on quantifying accelerator grid, screen grid, and discharge cathode keeper erosion. However the study of other ion thruster phenomena may be addressed in the process. For example, LIF velocimetry may facilitate the design of high-I $\mathrm{I}_{\mathrm{SP}}$ grids by providing intra-aperture velocity distributions at different locations across the radius of the grids. Realization of the laser diagnostic objectives described above will significantly improve the quality and process of ion thruster development.

GRC is pursuing an incremental approach to achieving these goals. At each stage, the feasibility of pursuing more demanding capabilities will be evaluated. In addition to applying traditional diagnostic techniques, new techniques such as LDI and, in parallel, density calibration cells are being developed.

The power conversion of the pulsed dye laser constitutes the most immediate challenge to meeting the goals of direct erosion measurements. An investment tradeoff analysis is underway in case the laser proves incapable of generating sufficient fluorescence. Other issues include improving mode quality and thereby the beam waists at foci of beams delivered via fiber optics, improving the signal collection capability in a vacuum facility with poor optical access, and developing an interrogation point translation capability which does not jeopardize propellant feed system integrity.

\section{References}

1 Patterson, M. J., et al., "2.3 kW Ion Thruster Wear Test," AIAA-95-2516, $31^{\text {st }}$ Joint Propulsion Conference (July, 1995).

2 Polk, J. E., et al., "A 1000-Hour Wear Test of the NASA NSTAR Ion Thruster," AIAA-96-2717, $32^{\text {nd }}$ Joint Propulsion Conference (July, 1996).

${ }^{3}$ Polk, J. E., "An Overview of the Results from an 8200 Hour Wear Test of the NSTAR Ion Thruster,' AIAA99-2446, 35 $5^{\text {th }}$ Joint Propulsion Conference (June, 1999).
${ }^{4}$ Anderson, J. R., et al., "Results of an On-Going Long Duration Ground Test of the NSTAR Ion Thruster," AIAA-99-2446, 35 ${ }^{\text {th }}$ Joint Propulsion Conference (June, 1999).

5 Domonkos, M. T. and G. J. Williams, "Status of RealTime Laser Based Ion Engine Diagnostics at NASA Glenn Research Center," IEPC-01-304, $27^{\text {th }}$ International Electric Propulsion Conference (October, 2001).

${ }^{6}$ Williams, G. J., et al., "30 cm Ion thruster Discharge Cathode Erosion," IEPC-01-306, 27 ${ }^{\text {th }}$ International Electric Propulsion Conference (October, 2001).

7 Foster, J. E. and M. J. Patterson, 'Plasma Emission Characteristics from a High Current Hollow Cathode in a Ring-Cusp Discharge Chamber," AIAA-20024102, $38^{\text {th }}$ Joint Propulsion conference (July, 2002).

8 Williams, G. J., et al., "Near-field Plasma Characterization of a 15 A Hollow Cathode via Laser Diagnostics, AIAA-2002-2192, 23 ${ }^{\text {rd }}$ Plasmadynamics and Lasers Conference (May, 2002).

9 Rawlin, V. K., et al., "Status of Ion Engine Development for High Power, High Specific Impulse Missions," IEPC-01-096, 27 $7^{\text {th }}$ International Electric Propulsion Conference (October, 2001).

10 Rock, B. A., Development of an Optical Emission Model of the Determination of Sputtering Rates in Ion Thruster Systems, Ph.D. Dissertation, Arizona State University, 1984, pp 43-59.

11 Gaeta, C. J., et al., "Erosion Rate diagnostic in Ion Thrusters Using Laser-Induced Fluorescence," Journal of Propulsion and Power, 9 (3) 1993, 369376.

${ }^{12}$ Patterson, M. J., et al., "NEXT: NASA's Evolutionary Xenon Thruster," AIAA-2002-3832, $38^{\text {th }}$ Joint Propulsion Conference (July, 2002).

13 Soulas, G. C., "Improving the Total Impulse Capability of the NSTAR Ion Thruster with ThickAccelerator Grid Ion Optics," IEPC-01-081, 27 International Electric Propulsion Conference (October, 2001).

14 Emhoff, J. W. and I. D. Boyd, "Modeling Erosion and Backstreaming Ions in the Optics of the NSTAR 
Thruster," IEPC-01-079, 27 $7^{\text {th }}$ International Electric Propulsion Conference (October, 2001).

15 Wang, J., et al., "3-D Particle Simulations of NSTAR Ion Optics," IEPC-01-085, 27 ${ }^{\text {th }}$ International Electric Propulsion Conference (October, 2001).

${ }^{16}$ Nakayama, Y., and P. J. Wilbur, "Numerical Simulation of High Specific Impulse Ion thruster Optics," IEPC-01-099, 27 ${ }^{\text {th }}$ International Electric Propulsion Conference (October, 2001).

17 Domonkos, M. T., and R. E. Stevens, "Absolute density Calibration Cell for Laser Induced Fluorescence Erosion Rate Measurements," IEPC-01$300, \quad 27^{\text {th }}$ International Electric Propulsion Conference (October, 2001).

18 Rawlin, V. K., et al., "High-Power, High Specific Impulse Ion Engine Operation," AIAA-2002-3838, $38^{\text {th }}$ Joint Propulsion Conference (July, 2002).

${ }^{19}$ Smith T. and A. D. Gallimore, Personal Communication, The Plasmadynamics and electric Propulsion Laboratory, Dept. of Aerospace
Engineering, the Univeristy of Michigan, March, 2002.

${ }^{20}$ Smith, T. B., et al., "Deconvolution of Axial Velocity Distributions from hall thruster LIF Spectra," IEPC01-019, $27^{\text {th }}$ International Electric Propulsion Conference (October, 2001).

${ }^{21}$ Smith, T. B., et al., "Deconvolution of Axial Velocity Distributions from Hall Thruster LIF Spectra," AIAA-2002-3880, 38 ${ }^{\text {th }}$ Joint Propulsion Conference (July, 2002).

22 Griem, H. R., Plasma Spectroscopy, McGraw Hill, New York, 1964, pp 145-153.

23 Domonkos, M. T., et al., "Investigation of Keeper Erosion in the NSTAR in the NSTAR Ion Thruster," IEPC-01-308, 27 ${ }^{\text {th }}$ International Electric Propulsion Conference (October, 2001).

24 Mantenieks, M. A., et al., "Low Energy Xenon Ion Sputtering Yield Measurements," IEPC-01-309, $27^{\text {th }}$ International Electric Propulsion Conference (October, 2001). 
Table 1: Summary of erosion and plasma parameters with direct measurement capabilities noted for an arbitrary ion thruster.

\begin{tabular}{|c|c|c|c|}
\hline Diagnostic target & Current diagnostic capability & Concerns with the current capability & $\begin{array}{l}\text { Issues complicating direct, non-intrusive } \\
\text { measurement }\end{array}$ \\
\hline $\begin{array}{l}\text { Accelerator grid: } \\
\text { Pit and grove erosion }\end{array}$ & $\begin{array}{l}\text { - Post test inspection and mass loss } \\
\text { measurement } \\
\text { - LIF demonstrated } \\
\text { - Digital photography }\end{array}$ & $\begin{array}{l}\text { - Sputtered atoms interrogated by the laser come } \\
\text { from different locations } \\
\text { - Laser power required for typical erosion drives } \\
\text { high costs } \\
\text { - Long testing duration required to observe a } \\
\text { diameter change } \\
\end{array}$ & $\begin{array}{l}\text { Typical orifice dimensions reduce erosion } \\
\text { sites to regions smaller than laser beam } \\
\text { diameters }\end{array}$ \\
\hline $\begin{array}{l}\text { Accelerator grid: } \\
\text { Inner wall erosion }\end{array}$ & $\begin{array}{l}\text { - Post test inspection } \\
\text { - Digital photography } \\
\text { - Optical emission spectroscopy }\end{array}$ & $\begin{array}{l}\text { - Long testing duration required to observe a } \\
\text { diameter change } \\
\text { - Non-cylindrical walls may mask erosion }\end{array}$ & $\begin{array}{l}\text { - Typical orifice diameters are smaller than } \\
\text { typical laser beams. } \\
\text { - Laser delivery and fluorescence collection } \\
\text { optics must be in the beam. }\end{array}$ \\
\hline $\begin{array}{l}\text { Screen grid upstream surface } \\
\text { erosion }\end{array}$ & $\begin{array}{l}\text { - Post test inspection } \\
\text { - Bias currents } \\
\text { - Optical emission spectroscopy }\end{array}$ & $\begin{array}{l}\text { - Accel and screen grid are typically of the same } \\
\text { material } \\
\text { - Plasma potential near the grid unknown }\end{array}$ & $\begin{array}{l}\text { - Optical access blocked by accel grid. } \\
\text { - Accel and screen grid are typically of the } \\
\text { same material }\end{array}$ \\
\hline $\begin{array}{l}\text { Discharge cathode keeper } \\
\text { erosion }\end{array}$ & $\begin{array}{l}\text { - Post test inspection } \\
\text { - Digital photography } \\
\text { - Optical emission spectroscopy }\end{array}$ & $\begin{array}{l}\text { - Grids and keeper typically of the same material } \\
\text { - Long testing duration required to observe a } \\
\text { diameter change } \\
\text { - Surface contouring masked }\end{array}$ & $\begin{array}{l}\text { - Optical access through the grids. } \\
\text { - Grids and keeper typically of the same } \\
\text { material }\end{array}$ \\
\hline $\begin{array}{l}\text { Discharge cathode orifice plate } \\
\text { erosion }\end{array}$ & $\begin{array}{l}\text { - Post test inspection } \\
\text { - Digital photography } \\
\text { - Optical emission spectroscopy }\end{array}$ & $\begin{array}{l}\text { Long testing duration required to observe a } \\
\text { diameter change } \\
\text { - Surface contouring masked }\end{array}$ & $\begin{array}{l}\text { - Optical access through the grids. } \\
\text { - Orifice plate covered by keeper }\end{array}$ \\
\hline $\begin{array}{l}\text { Energy, charge state, and } \\
\text { density of ions impacting accel } \\
\text { grid downstream surface }\end{array}$ & $\begin{array}{l}\text { - Faraday and ExB probe measurements at } \\
\text { least several millimeters downstream } \\
\text { - Impingement current } \\
\text { - LIF demonstrated }\end{array}$ & $\begin{array}{l}\text { - } \mathrm{J}_{\mathrm{A}} \text { integrated over entire grid } \\
\text { - Ions collected from multiple locations }\end{array}$ & $\begin{array}{l}\text { Typical orifice dimensions reduce } \\
\text { beamlets to regions smaller than laser } \\
\text { beam diameters } \\
\text { - Ground states of neutral and singly } \\
\text { ionized propellant inaccessible-requires } \\
\text { detailed modeling }\end{array}$ \\
\hline $\begin{array}{c}\text { Energy, charge state and } \\
\text { density of ions impacting accel } \\
\text { grid orifice walls }\end{array}$ & $\begin{array}{l}\text { - Faraday and ExB probe measurements at } \\
\text { least several millimeters downstream } \\
\text { - Impingement current }\end{array}$ & $\begin{array}{l}\text { - } \mathrm{J}_{\mathrm{A}} \text { integrated over entire grid } \\
\text { - Ions collected from multiple locations }\end{array}$ & $\begin{array}{l}\text { Typical orifice dimensions reduce } \\
\text { beamlets to regions smaller than laser } \\
\text { beam diameters }\end{array}$ \\
\hline $\begin{array}{l}\text { Energy, charge state, and } \\
\text { density of ions impacting } \\
\text { screen grid upstream surface }\end{array}$ & $\begin{array}{l}\text { - Faraday and ExB probe measurements at } \\
\text { least several millimeters downstream } \\
\text { - Impingement current }\end{array}$ & - All plasma data collected downstream & - Optical access through grids \\
\hline $\begin{array}{c}\text { Energy, charge state, and } \\
\text { density of ions impacting } \\
\text { discharge cathode assembly } \\
\text { surfaces } \\
\end{array}$ & $\begin{array}{l}\text { - Faraday and ExB probe measurements at } \\
\text { least several millimeters downstream }\end{array}$ & - All plasma data collected downstream & - Optical access through grids \\
\hline $\begin{array}{c}\text { Plasma density variations in the } \\
\text { discharge chamber }\end{array}$ & $\begin{array}{l}\text { - Optical emission sectroscopy } \\
\text { - Faraday and ExB probe measurements at } \\
\text { least several millimeters downstream }\end{array}$ & $\begin{array}{l}\text { - All plasma data collected downstream } \\
\text { - OES integrated through chamber }\end{array}$ & $\begin{array}{l}\text { - Optical access through grids } \\
\text { - Integrated measurements }\end{array}$ \\
\hline
\end{tabular}


Table 2: Infrared Transitions Accessible to the diode Laser of Species Potentially Targeted for Ion Thruster Plasma Characterization

\begin{tabular}{|c|c|c|}
\hline Species & $\begin{array}{c}\text { Laser Wavelength } \\
(\mathrm{nm})\end{array}$ & $\begin{array}{c}\text { Fluorescing Wavelength } \\
(\mathrm{nm})\end{array}$ \\
\hline Xe I & 834.682 & 820.634 \\
\hline Xe I & 840.919 & 823.163 \\
\hline Xe II & 834.724 & 542.915 \\
\hline Kr I & 826.324 & 587.092 \\
\hline Mo I & 838.932 & 824.506 \\
\hline
\end{tabular}

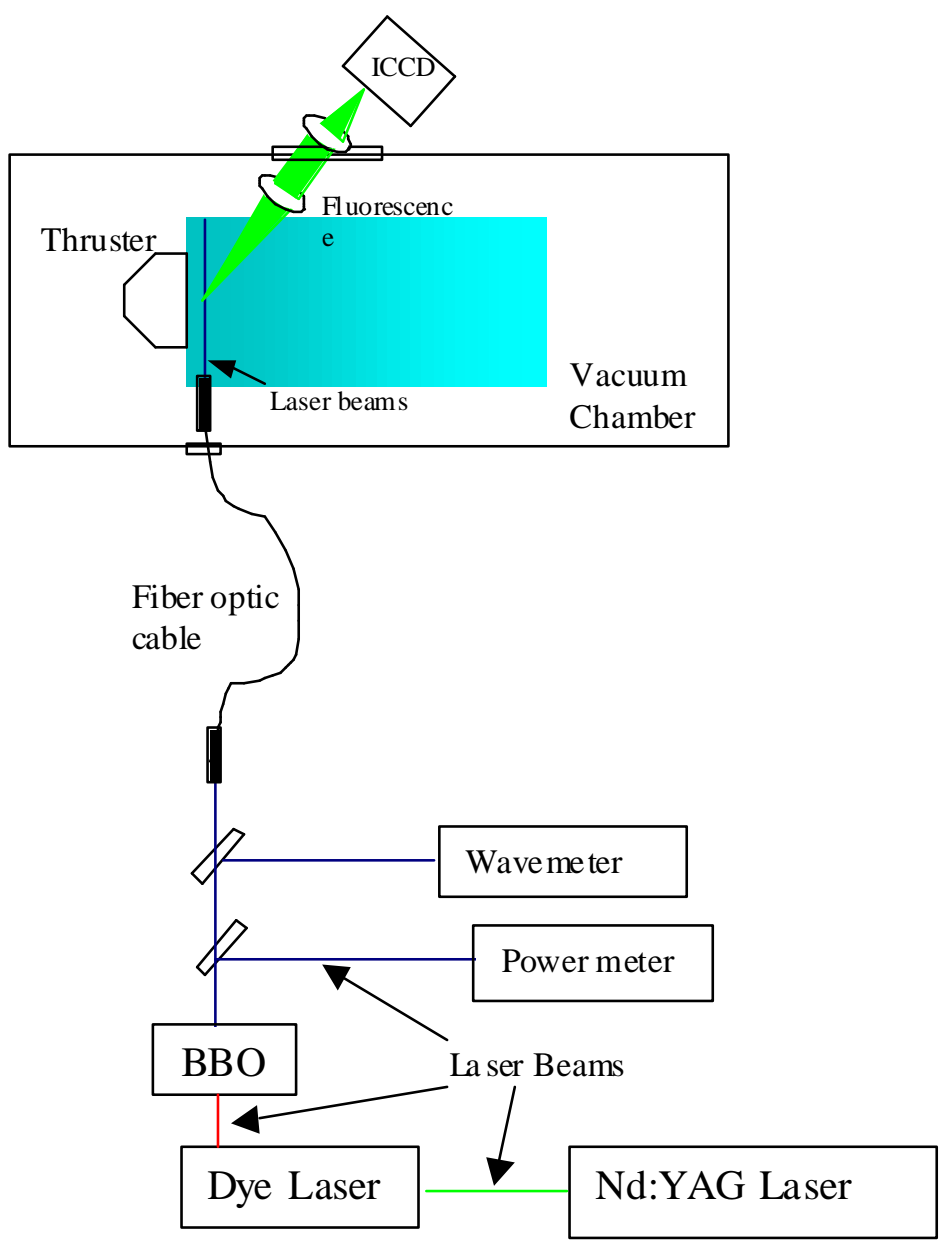

Figure 1 Schematic of the pulsed laser system. 


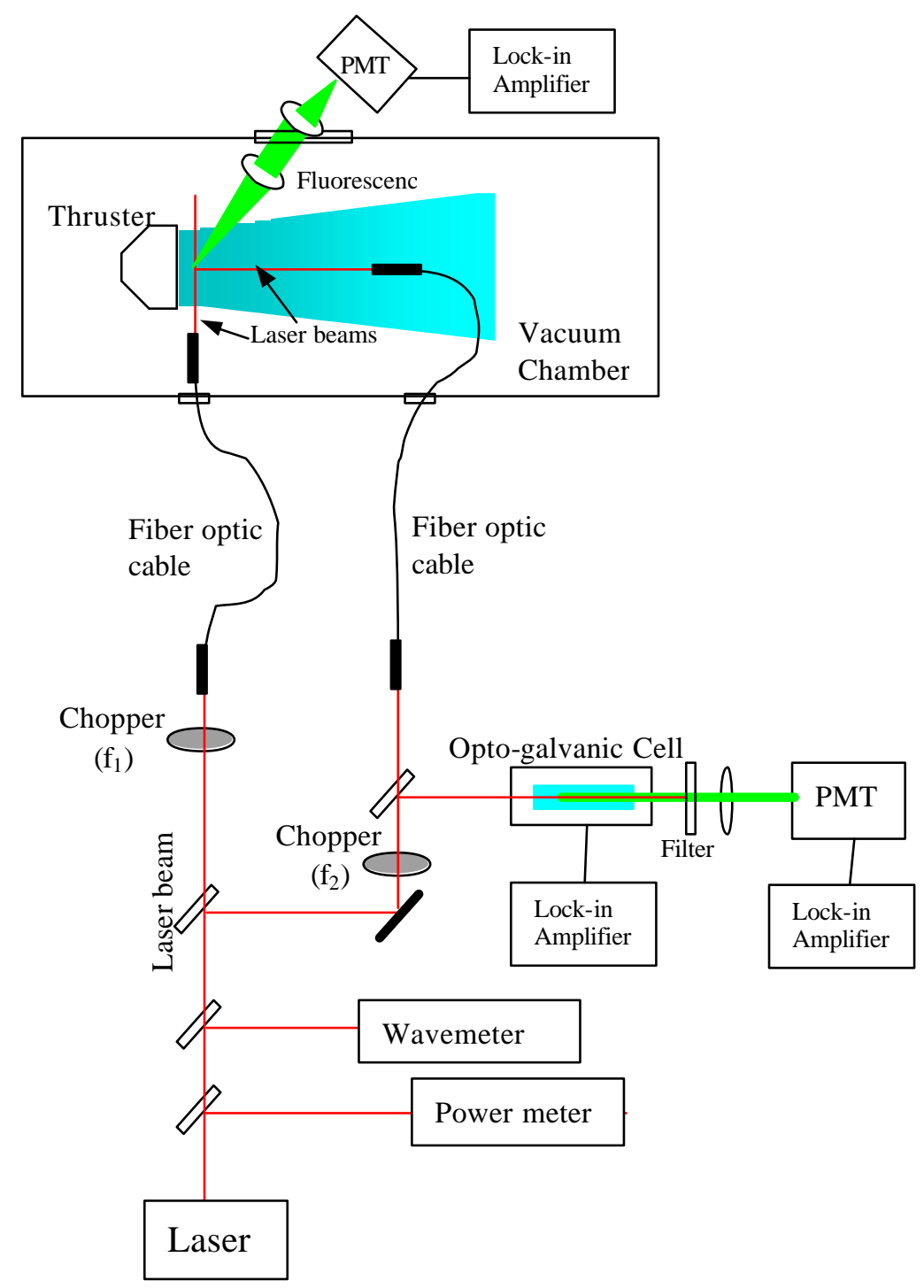

Figure 2 Schematic of the cw diode laser system 


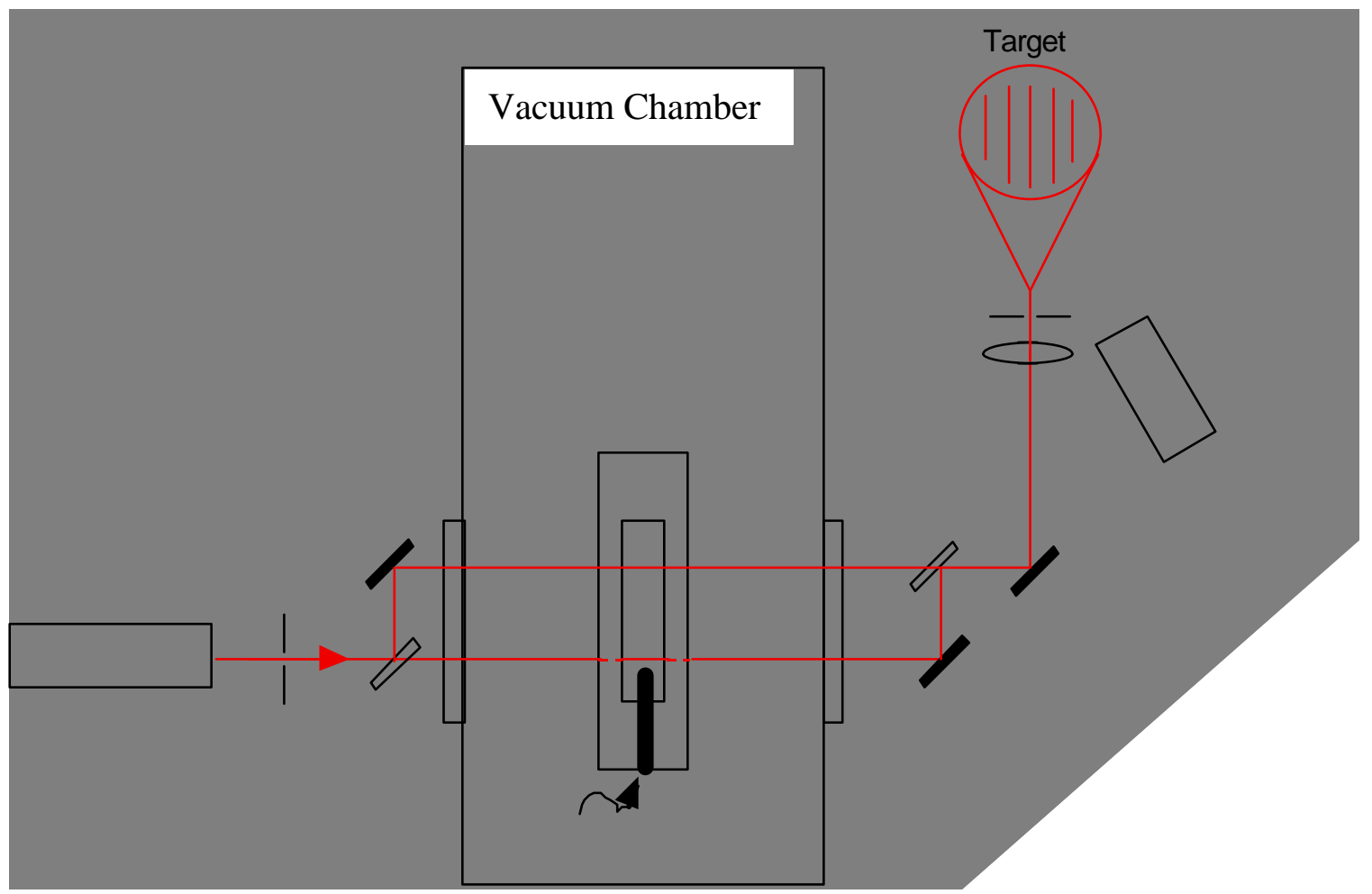

Figure 3 Schematic diagram of LDI interrogating the plasma downstream of an HCA.

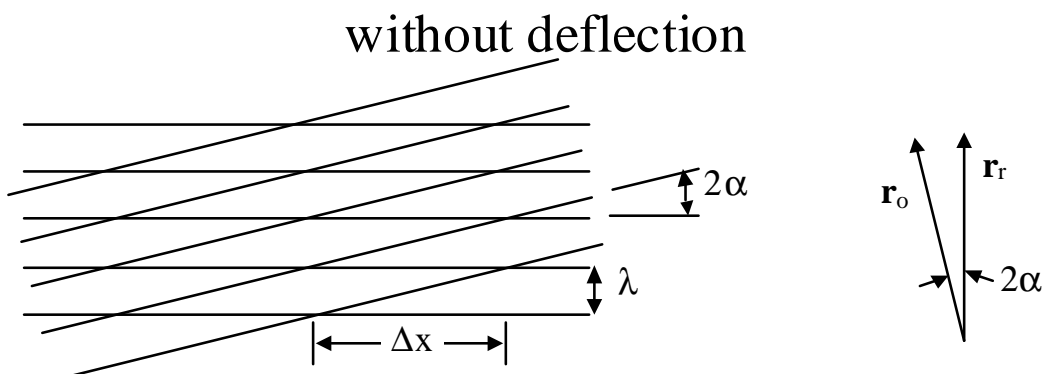

with deflection

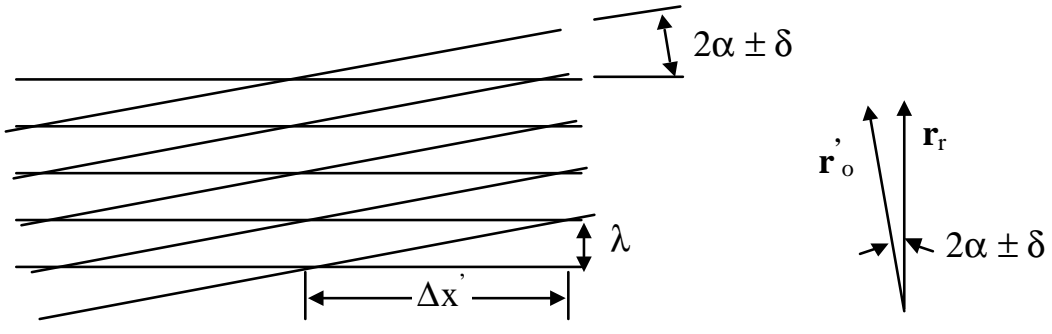

Figure $4 \mathrm{~A}$ comparison of fringe spacing with and without deflection of he object beam of the interferometer by the plasma gradient. ${ }^{8}$ 


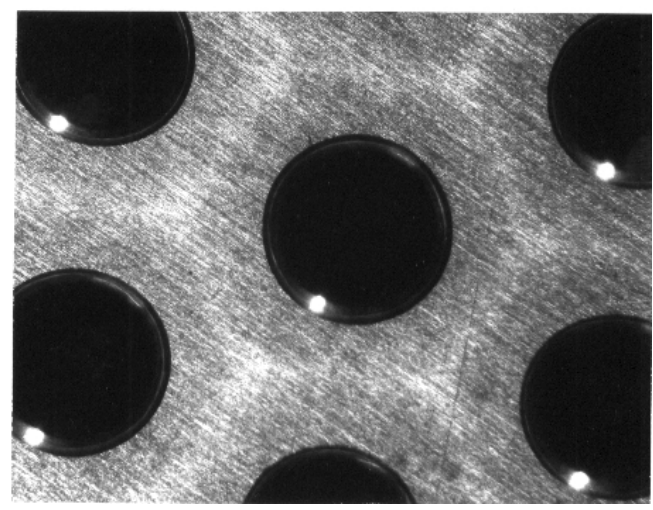

New Grid

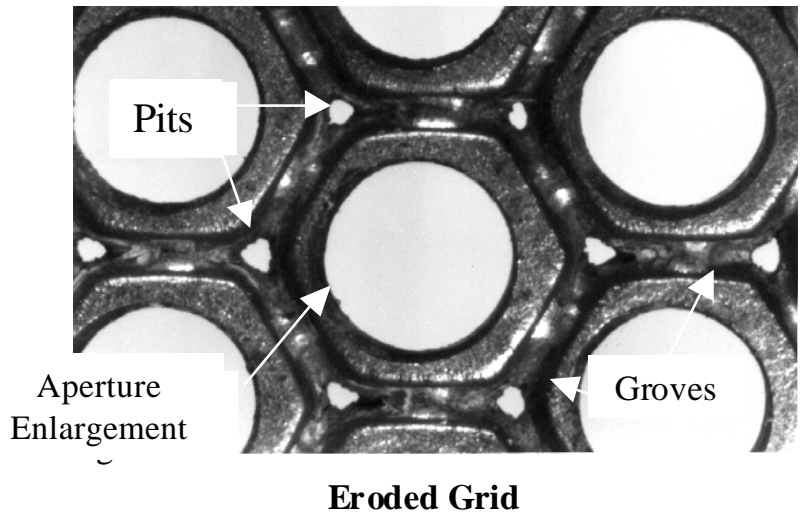

Figure 5 Photographs of the downstream surface of the accelerator grid showing the three regions of erosion. ${ }^{13}$
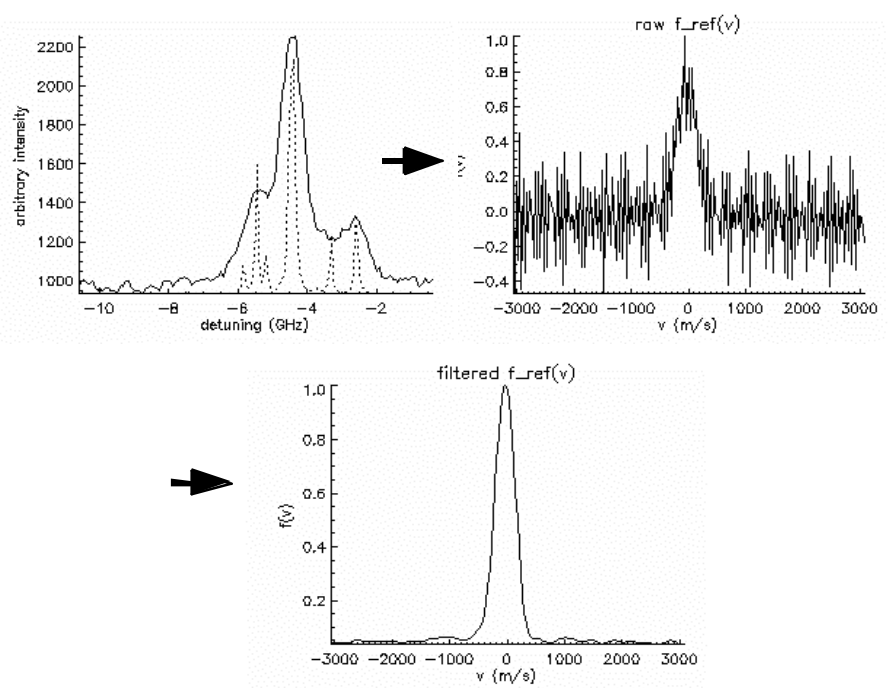

Figure 6 The steps to resolve velocity distributions from an LIF spectrum: ${ }^{20}$ First the spectrum is deconvolved based on the transition's fine structure to yield a velocity distribution. Then the noisy velocity distributions are filtered and averaged to yield a high-resolution velocity distribution. 
Cathode Orifice Plate

Erosion near outer diameter

- $160 \mu \mathrm{m} / \mathrm{kr}$

- E-beam weld now flush

Only surface-contouring near the orifice chamfer

Raytracing indicates a pointsource 7.4 to $10.8 \mathrm{~mm}$ downstream
Cathode Tube

Downstream edge eroded

- $275 \mu \mathrm{m} / \mathrm{khr}$

- Edge curved

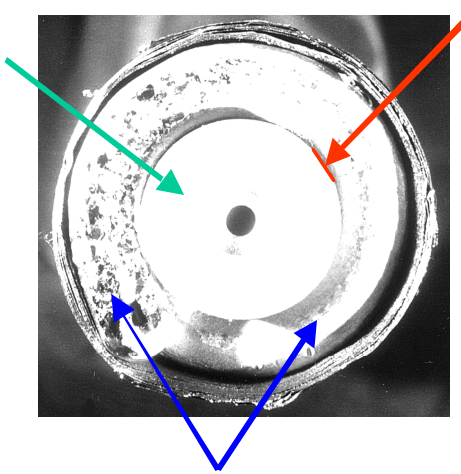

Raytracing consistent with orifice plate erosion

Sheath effects might account for curved edge

\section{Cathode Heater}

Before test, extended downstream of orifice plate After test, flush with orifice plate

Raytracing suggests a point-source within $1 \mathrm{~mm}$ of orifice

Figure 7 A summary of the DCA erosion observed in the $2000 \mathrm{hr}$ wear test. ${ }^{1,6}$

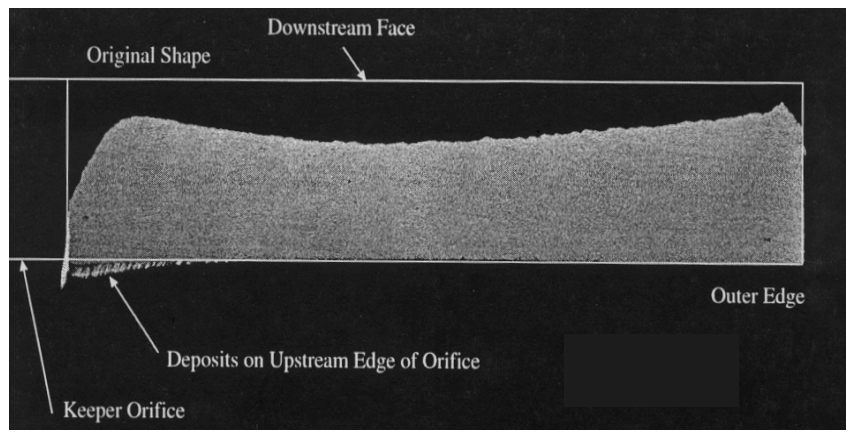

a. Cross section of the keeper orifice plate after $8200 \mathrm{hrs}$ in the LDT. ${ }^{3}$

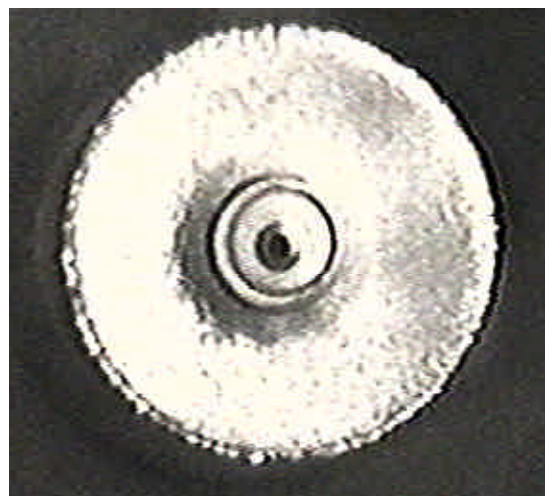

b. End on view of the DCA after $8100 \mathrm{hrs}$ of the ELT

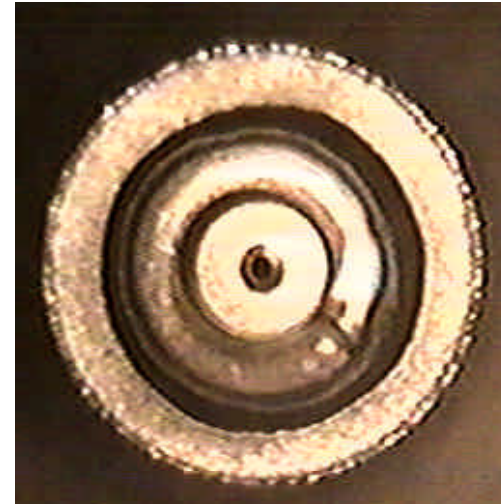

c. End on view of the DCA after $21000 \mathrm{hrs}$ of the ELT

Figure 8 Keeper erosion for two different wear tests. ${ }^{4}$ 